\title{
HONEY BEE POLLINATION OF CANTALOUPE, CUCUMBER, AND WATERMELON
}

\author{
Eric C. Mussen, Extension Apiculturist, Department of Entomology, University of California, Davis; and \\ Robbin W. Thorp, Professor Emeritus, Department of Entomology, University of California, Davis
}

$C^{4}$ ucurbits (the Cucurbitaceae family, including melons, cucumbers, gourds, squashes, and pumpkins) contribute significantly to agricultural production in California, with nearly $\$ 250$ million in fresh fruit and seed produced annually. A large portion of the edible production (45 percent) occurs in Fresno, Kern, Riverside, Merced, and Tulare Counties. A substantial portion of the seed crop is grown in the Sacramento Valley. Honey bees are the pollinator of choice for cucurbit production.

\section{WHY HONEY BEE POLLINATION IS NECESSARY}

Cucurbit vines usually have two kinds of flowers. Most cantaloupes (muskmelon, Cucumis melo var. reticulatus) and mixed melons (Cucumis melo, indorous group) such as casaba, crenshaw, honeydew, and Persian have male (staminate) flowers as well as bisexual or perfect (hermaphroditic) fruit-producing flowers. Most cucumbers (Cucumis sativus) and watermelons (Citrullus lanatus) have male flowers and female (pistillate) fruit-producing flowers. Insect pollination is necessary, especially for commercial fruit set, because the large, sticky pollen grains cannot be moved by the wind. Some cucurbits, such as seedless, parthenocarpic, slicing cucumbers, do not need pollinators.

Cucurbit fruit have many seed. Each seed forms from the union of the contents of a single pollen grain and a single ovule. Misshapen and undersized fruit are often caused by inadequate pollination (low numbers of fertilized seed). Successful fruit production requires many visits by pollen-coated bees to ensure the transfer of about 500 to 1,000 large, viable pollen grains from the flower's male organ (anther) to the stigma of the female organ. Even triploid watermelon, with seed that abort shortly after fertilization, needs to be pollinated in order to produce enough hormone to stimulate quality fruit growth.

Bees forage on cucurbit flowers for nectar, the bees' energy source, and pollen, their source of protein, vitamins, minerals, and lipids. Pollen that is packed on the bees' legs is unavailable for pollina- tion. The pollen grains picked up from male flowers on the body hairs of the bees, however, rub off during successive visits to female flowers. Bees are active when flowers are most receptive. Collection of pollen by bees usually ends before noon, but nectar collection continues into late afternoon. Bees visit the fruit-producing flowers more often than the male blossoms and stay on them longer.

\section{FLOWER DROP}

Cucurbit flowers are usually open for only 1 day. Male flowers appear first, produce pollen, become senescent, and drop off. There is often more than one male flower produced for each fruiting flower. Unpollinated fruit-producing flowers also abort and drop off. In addition, developing fruit can temporarily inhibit the development of other fruit-producing flowers on the same runner or the same vine. A large combined drop of male and fruit-producing flowers does not necessarily mean that the crop is threatened. Each runner can theoretically produce two to four fruit, but field experience suggests that an average of one to two per plant should be expected. Growers should estimate fruit set from a count of developing fruit, not from the number of hermaphroditic blossoms or from blossom drop.

\section{TIMING BEE INTRODUCTION}

Adequate numbers of honey bees must be provided at the right time to avoid losses from unpollinated flowers. Honey bee colonies should be placed in cucurbit fields or on their borders as soon as the first fruit-producing flowers appear. For melons, if adequate pollination is provided to set the maximum number of crown flowers, the melons produced will be sweeter and larger, of uniform size, and will have one-third fewer "harvest picks" (the number of times pickers must harvest the field). Earlier melons, especially cantaloupes and honeydews, often bring a premium price, so most growers try for the earliest possible production date. A 14-day delay in the introduction of bees after bloom begins may not 
reduce total yield, but it will delay the harvest peak and sacrifice the high quality of the crown set. For most varieties of cucumbers and watermelons, introduce bee colonies when the first flowers appear.

\section{COLONY STRENGTH}

Colony population determines the number of foraging bees available to pollinate cucurbit flowers and also determines the size of the brood that can be reared, which in turn creates the pollen demand. A good practice is to rent colonies from beekeepers who can supply the greatest number of frames covered with bees and the most square inches of brood.

The California State Beekeepers' Association has set as its minimum standard colony for alfalfa pollination 5 frames covered with bees and 600 square inches of brood at field introduction time. Because pollination of alfalfa seed fields and cucurbit (melon) fields occurs at about the same time in central California, growers should consider this as the minimum-strength colony for cucurbit pollination and be aware that significantly stronger colonies should be available and will provide much better results.

\section{COLONY NUMBERS}

The number of bee colonies needed for adequate cucurbit pollination is influenced by how much the bees are attracted to surrounding crops and blooming weeds. Cucurbit flowers are usually attractive because they are good producers of concentrated nectar. However, because the low number of flowers per acre provides less total nectar than do many other floral sources, honey bees may seek the more productive nectar sources, reducing cucurbit pollination. Competition from other floral sources can be greatly reduced by placing the colonies of bees within the cucurbit field.

It may be advisable to use more than the minimum one colony per acre. Increasing the number of colonies from 1 to 2 or 3 per acre (2.5 to 5 or 7.5 per ha) has several advantages:

- Blossom-setting period is decreased by 1 week or more;

- A higher quality marketable crop results: 50 more crates per acre (125 per ha) with 2 colonies; 100 more crates per acre ( 250 per ha) with 3 ; and

- Harvest period advanced 1 week or more and shortened by 1 week, reducing the number of picks by 33 percent.
Increasing the number of colonies per acre decreases the amount of cucurbit nectar and pollen available to each colony. Growers must be willing to pay premium rental fees where experience has shown that colony strength is reduced by increased foraging competition.

Also, special situations may increase the need for more colonies than the often-recommended 1 colony per acre (2.5 per ha). Destructive (once-over) mechanical harvesting, especially for recently developed pickling cucumbers, requires higher plant densities and involves increasing the number of female flowers through the use of gynecious varieties (varieties with all female flowers) or chemically induced female plants. Therefore, efficient pollen transfer is essential, which requires large populations of honey bee foragers from strong colonies. Since the pollination period is so short, colony introduction and removal must be precisely timed to ensure pollen transfer throughout the flowering period and to produce a uniform, maximum crop.

\section{COLONY DISTRIBUTION}

Honey bee colonies placed at the edge of a field provide twice as many visits to melon blossoms as colonies placed at some distance from the field. Groups of colonies spaced about $1 / 10$ mile $(160 \mathrm{~m})$ apart around the periphery of a field provide a more uniform cucurbit set than a single apiary at one end of the field. However, colonies located within a field will have about twice as many bees visiting the field's blossoms as there would be if the same number of colonies were located along the field's periphery.

If the field is less than 40 acres (16 ha), colonies may be placed in groups of 10 to 20 down the field's centerline to produce maximum pollination. If there are no competing crops or weeds nearby, an alternative would be to place the colonies in groups of 10 to 20 along the borders on at least two sides of the field, preferably toward the center along the longer borders of the field.

For maximum and uniform pollination in fields larger that 40 acres (16 ha), the colonies should be located within the fields in drops of 8 to 20 colonies each along the bee drives (the paths where a truck is driven to drop off colonies). The outermost bee drives should be approximately $1 / 20$ mile $(80 \mathrm{~m})$ in from the border of the fields and drives should be about $1 / 10$ mile $(160 \mathrm{~m})$ apart. Neither the bee drives nor the bee drops along the drives should be more than $1 / 8$ mile $(200 \mathrm{~m})$ apart (the distance would vary with the number of colonies per drop). 


\section{PESTICIDE HAZARDS TO HONEY BEES}

To minimize pesticide hazards, place bees in the field or on its borders only when the bees are needed. Remove the bees from the field as soon as the crop has set (usually after 3 to 4 weeks).

Once the bees have been placed in the field, applications of bee-toxic pesticides should be avoided whenever possible. When economically essential, pesticides toxic to bees should be applied only in late evening or at night, when cooler temperatures have driven bees back into the hives. The loss of foraging bees the next day will impact crop yield substantially for many following days.

Pesticides nontoxic to bees may be applied during the day when bees are visiting flowers. It is safer not to apply insecticides over hives. Use sprays, not dusts. Current recommendations for use of chemicals to control pests and diseases are available in the UC IPM Pest Management Guidelines (DANR Publication 3339), available at county Cooperative Extension offices or on the World Wide Web at http://www.ipm.ucdavis.edu. Daytime spraying or overhead irrigation should be avoided early in the day to prevent soaking pollen or diluting nectar and inhibiting visitation that day.

If a beekeeper wishes to be notified 48 hours before a bee-toxic pesticide application, he or she must submit a specific request to the agricultural commissioner of the county in which the apiaries are located. To avoid moving colonies into bee-toxic residues, a beekeeper should submit the request for proposed apiary sites 3 days before locating colonies on the site.

\section{POLLINATION CONTRACTS}

A written contract signed by the beekeeper and grower usually ensures better pollination service. Consider the following when preparing a contract:

- Stage of bloom when bees are to be moved into and out of field;

- Number of frames of bees and brood to be provided at anticipated date;

- Description of colony distribution pattern in the field;

- Rental fee and date payable;

- Grower's assurance that no pesticide harmful to honey bees will be used, or that, if it is necessary to use pesticides, the grower will give 48-hour notice;

- Grower's promise to pay for extra movement of colonies into and out of the field or within the field;

- Grower's promise to provide easy access into and out of field or within field (bee drives) and to avoid digging irrigation ditches that would isolate apiary locations;

- Beekeeper's promise to inspect his or her bees before and while in the field, and to maintain them in good condition for pollination; and

- Consult local ordinances concerning placement of bees near roads and buildings.

The University of California, in accordance with applicable Federal and State law and University policy, does not discriminate on the basis of race, color, national origin, religion, sex, disability, age, medical condition (cancer-related), ancestry, marital status, citizenship, sexual orientation, or status as a Vietnam-era veteran or special disabled veteran. The University also prohibits sexual harassment. This publication is available in alternative media on request. Inquiries regarding the University's nondiscrimination policies may be directed to the Affirmative Action Director, University of California, Agriculture and Natural Resources, 300 Lakeside Drive, 6th Floor, Oakland, CA 94612-3560; (510) 987-0096. 